\title{
EL USO DEL LENGUAJE NO SEXISTA COMO INSTRUMENTO PARA CONSEGUIR LA IGUALDAD REAL Y EFECTIVA
}

\author{
The use of non-sexist language as a tool \\ to achieve real and effective equality
}

\author{
Cecilia Rosado-Villaverde \\ Profesora Contratada Doctora de Derecho Constitucional \\ Universidad Rey Juan Carlos
}

http://dx.doi.org/10.18543/ed-69(2)-2021pp229-248

Recibido: 8.12.2021

Aceptado: 13.12 .2021

\section{Resumen}

La consecución de la igualdad real y efectiva es uno de los elementos indispensables de nuestros sistemas democráticos. El art. 9.2 de nuestra Constitución establece que son los poderes públicos los encargados de promover las condiciones para que la igualdad sea real y, además, deben remover los obstáculos que impidan su plenitud. Para ello, los poderes públicos deben dotarse de diferentes herramientas que sean efectivas para la consecución de sus objetivos. El uso del lenguaje no sexista, que ya fue planteado en la esfera de la lingüística en los años setenta del siglo XX, es un recurso que las instituciones internacionales, europeas y nacionales han legislado para evitar que nuestro lenguaje, a través del cual nos comunicamos y nombramos los objetos materiales e inmateriales, invisibilice a las mujeres y perpetúe las discriminación histórica y estructural que sufren.

\section{Palabras clave} jurídico.

Igualdad, discriminación, lenguaje no sexista, Constitución, ordenamiento 


\begin{abstract}
The achievement of real and effective equality is one of the necessary elements of our democratic systems. Article 9.2 of our Constitution establishes that it is the public authorities that are responsible for promoting the conditions for equality to be real and must remove the obstacles that prevent its fullness. The public authorities must different tools that are effective in achieving their objectives. The use of non-sexist language - which was already manifested in the field of linguistics in the Seventies of the Twentieth Century - is a resource that international, European and national institutions have legislated to prevent our language, which we communicate and name the material and immaterial objects, from making women invisible and perpetuating the historical and structural discrimination they suffer.
\end{abstract}

\title{
Key words
}

Equality, discrimination, non-sexist language, Constitution, legal system. 


\begin{abstract}
SUMARIO: I. INTRODUCCIÓN. II. LA CONSTITUCIONALIDAD DEL LENGUAJE NO SEXISTA. III. CONCEPTO Y SIGNIFICACIÓN DEL LENGUAJE NO SEXISTA. IV. INFORME DE LA REAL ACADEMIA ESPAÑOLA SOBRE LA INCLUSIÓN DE LENGUAJE NO SEXISTA EN LA CONSTITUCIÓN ESPAÑOLA. V. CONCLUSIONES. VI. Bibliografía
\end{abstract}

\title{
I. INTRODUCCIÓN
}

La Ley Orgánica 3/2007, de 22 de marzo, para la igualdad efectiva de mujeres y hombres, reconoce en su artículo 14, apartado 11, que uno de los criterios de actuación de los poderes públicos debía ser «La implantación de un lenguaje no sexista en el ámbito administrativo y su fomento en la totalidad de las relaciones sociales, culturales y artísticas». Asimismo, el art. 24 de esta Ley, dedicado a la integración del principio de igualdad en la política de educación, expresa en su apartado segundo, punto c), que «Las Administraciones educativas, en el ámbito de sus respectivas competencias, desarrollarán, con tal finalidad, [...] La eliminación y el rechazo de los comportamientos y contenidos sexistas y estereotipos que supongan discriminación entre mujeres y hombres, con especial consideración a ello en los libros de texto y materiales educativos». Esta norma legal también hace referencia al lenguaje no sexista en el Título III, dedicado a la Igualdad y los medios de comunicación ${ }^{1}$.

Desde la entrada en vigor de esta Ley Orgánica, el lenguaje no sexista ${ }^{2}$ se convirtió en uno de los factores necesarios para conseguir la igualdad

${ }^{1}$ El art. 36 dice que «Los medios de comunicación social de titularidad pública velarán por la transmisión de una imagen igualitaria, plural y no estereotipada de mujeres y hombres en la sociedad, y promoverán el conocimiento y la difusión del principio de igualdad entre mujeres y hombres». La importancia de las imágenes no sexistas también es un elemento fundamental que va unido al propio lenguaje inclusivo.

${ }^{2}$ El término lenguaje inclusivo incluye no sólo el lenguaje no sexista, sino que también se refiere al uso correcto, respetuoso y consensuado para hacer referencia a las personas con discapacidad física y orgánica. La importancia de no discriminar a las personas con discapacidad es fundamental para dar cumplimiento al art. 14 de la Constitución española. Y esa no discriminación debe comenzar por el propio uso del lenguaje. Ya la Ley 39/2006, de 14 de diciembre, de promoción de la autonomía personal y atención a las personas en situación de dependencia, establece en su Disposición adicional octava que «Las referencias que en los textos normativos se efectúan a «minusválidos» y a "personas con minusvalia», se entenderán realizadas a «personas con discapacidad». A partir de la entrada en vigor de la presente Ley, las disposiciones normativas elaboradas por las Administraciones Públicas utilizarán los términos "persona con discapacidad»o "personas con discapacidad» para denominarlas». Actualmente se encuentra en tramitación un proyecto de reforma constitucional que busca que se elimine el término disminuido del 
efectiva entre mujeres y hombres en nuestro país. Pero también comenzó la polémica en torno a este instrumento. Numerosos lingüistas y juristas, entre otras profesiones, han escrito ríos de tinta sobre lo superfluo del lenguaje inclusivo, su insignificante acción o lo inútil de su objetivo (Bosque Muñoz, 2009, 535; Bolívar, 2019, 355-375). También existen opiniones que defienden que su utilización es perjudicial para el propio uso lingüístico y que su empleo es nocivo para el desarrollo de nuestra lengua. Así que estamos ante una cuestión no exenta de controversia. No parece que estemos cerca de llegar a un consenso, más bien al contrario, en estos tiempos parece que se recrudece.

El lenguaje es fundamental para la formación de la identidad social de las personas, y ello supone que el buen uso del mismo es clave. La lengua no tiene porqué ser sexista o discriminatoria, es el empleo que se hace de ella el que crea contextos y situaciones donde se invisibiliza a las mujeres y se configuran imágenes en las que las mujeres ocupan papeles inferiores respecto de los hombres. El Informe sobre el lenguaje no sexista del Parlamento Europeo de 13 de febrero de 2008 decretó que: «La finalidad del lenguaje no sexista o lenguaje neutral en cuanto al género es evitar opciones léxicas que puedan interpretarse como sesgadas, discriminatorias o degradantes al implicar que uno de los sexos es superior al otro, ya que en la mayoría de los contextos el sexo de las personas es, o debe ser, irrelevante. La utilización de un lenguaje no sexista es algo más que un asunto de corrección política. El lenguaje influye poderosamente en las actitudes, el comportamiento y las percepciones. El Parlamento como institución respalda plenamente el principio de igualdad de género, y el lenguaje que utiliza debe reflejar este hecho»³.

No sólo la legislación española ${ }^{4}$ avala el lenguaje no sexista sino que también la Unión Europea lo ha incluido como un punto referencial de sus políticas. El principio de igualdad y no discriminación por razón de sexo y de género forma parte de los Tratados de la UE y de la Carta de los Derechos Fundamentales de la Unión. El Parlamento Europeo ha apoyado y defendido la igualdad de sexos y, a tal efecto, ha decidido que el uso de un lenguaje no sexista debe ser el adecuado para la consecución de este derecho fundamental. No podemos olvidar que la mencionada Ley Orgánica 3/2007 transpone dos directiva europeas, «2002/73/CE, de reforma de la Directiva 76/207/ CEE, relativa a la aplicación del principio de igualdad de trato entre hombres y mujeres en lo que se refiere al acceso al empleo, a la formación y a la

artículo 49 de la Constitución. Dicha reforma es una demanda de hace más de veinte años de los colectivos de personas con discapacidad.

${ }^{3}$ Este informe fue aprobado por la decisión Grupo de Alto Nivel sobre Igualdad de Género y Diversidad de 13 de febrero de 2008. Consultado en https://bit.ly/3ord0kF

${ }^{4}$ Las Comunidades Autónomas también poseen legislación en esta materia. 
promoción profesionales, y a las condiciones de trabajo; y la Directiva 2004/113/CE, sobre aplicación del principio de igualdad de trato entre hombres y mujeres en el acceso a bienes y servicios y su suministro» ${ }^{5}$.

El lenguaje no sexista ha sido respaldado por las instituciones europeas y españolas y por sus ordenamientos jurídicos. No es un aspecto puramente formal, sino que está dotada de un contenido específico que tiene funciones simbólicas, pero también funciones materiales. Este recurso ha venido para quedarse y es esencial entender cuáles son sus objetivos y cómo se debe emplear. Desde la lingüística encontramos numerosas guías y algunos manuales que explican cómo emplear nuestra lengua para eliminar su uso sexista. Aunque el propósito de estas páginas no es hacer una disertación lingüística, parece importante mencionar algunas reglas imprescindibles para entender este tema.

Desde el punto de vista constitucional se trata de entender si este lenguaje no sexista se encuentra dentro del amparo del artículo $14 \mathrm{y}$ del art. 9. 2 de nuestra Carta Magna. Además, debemos dilucidar si los textos internacionales que sirven de parámetro para la interpretación de nuestros derechos constitucionales también entienden que el lenguaje no sexista forma parte de los medios amparados en la conceptualización de sus textos. Sin olvidar el ámbito europeo, tanto de la Unión como del Consejo de Europa y sus manifestaciones en torno a esta materia que, como ya había anunciado anteriormente, despierta un encarnizado debate en torno a su necesidad, a su importancia y a su constitucionalidad.

\section{LA CONSTITUCIONALIDAD DEL LENGUAJE NO SEXISTA}

La igualdad entre mujeres y hombres se reconoce en numerosos textos internacionales como un principio jurídico universal. Centrándonos ahora en Naciones Unidas, cabe destacar la Declaración Universal de los Derechos Humanos, de 1948, en sus arts. 1, 2 y 7, la Convención relativa a la lucha contra las discriminaciones en la esfera de la enseñanza de 1960 (art. 1), ratificada por España en 1969, o la Convención sobre la eliminación de todas las formas de discriminación contra la mujer, de 1979 y ratificada por España en 1983. Asimismo, las cuatro Conferencias Mundiales de las Naciones Unidas para la Mujer fueron determinantes para lanzar nuevas herramientas en la lucha contra la discriminación por razón de $\operatorname{sexo}^{6}$. En la esfera internacional

${ }_{5}^{5}$ Exposición de motivos de la Ley Orgánica 3/2007, de 22 de marzo, para la igualdad efectiva de mujeres y hombres.

${ }^{6}$ Estas fueron la Conferencia Mundial de Ciudad de México (1975), la Conferencia Mundial de Copenhague (1980), la Conferencia Mundial de Nairobi (1985), y la Conferencia Mundial de Beijing (1995). 
el uso del lenguaje no sexista ha sido reconocido en diferentes momentos. Podemos destacar que la Declaración de Beijing, de 1995, establece que los medios de difusión deben presentar una imagen más justa de la mujer y deben utilizar un lenguaje que no sea sexista, y habla sobre la erradicación de los estereotipos sexistas en materia de comunicación, de educación y capacitación, de derechos humanos y de investigación. Del mismo modo, ONU Mujeres publicó la «Guía de terminología y uso de lenguaje no sexista para periodistas, comunicadoras y comunicadores ${ }^{7}$, en 2017 . Se puede destacar también que en julio de 2019, Naciones Unidas creó la «Lista de verificación para usar el español de forma inclusiva en cuanto al género» ${ }^{8}$.

Por su parte, hay que destacar el papel de la UNESCO en la aprobación de diversos documentos jurídicos en materia de lenguaje no sexista. En 1987, la Resolución 14.1 aprobada por la Conferencia General de la UNESCO, en su $24^{\mathrm{a}}$ reunión, apartado 1 del párrafo 2 mantuvo y mantiene que hay que «adoptar, en la redacción de todos los documentos de trabajo de la Organización, una política encaminada a evitar, en la medida de lo posible, el empleo de términos que se refieren explícita o implícitamente a un solo sexo, salvo si se trata de medidas positivas en favor de la mujer». En 1989, la Resolución 109 aprobada por la Conferencia General de la UNESCO, en su $25^{\mathrm{a}}$ reunión, párrafo 3 recomendó «seguir elaborando directrices sobre el empleo de un vocabulario que se refiera explícitamente a la mujer, y promover su utilización en los Estados Miembros; y velar por el respeto de esas directrices en todas las comunicaciones, publicaciones y documentos de la Organización».

En el contexto europeo, la Unión Europea reconoce que la igualdad es un principio fundamental. El Tratado de Ámsterdam (1999) afirma por primera vez que la igualdad entre mujeres y hombres y la eliminación de las desigualdades entre unas y otros es un objetivo que debe integrarse en todas las políticas y acciones de la Unión y de sus miembros. La Exposición de Motivos de la Ley Orgánica 3/2007, dice que «con amparo en el antiguo artículo 111 del Tratado de Roma, se ha desarrollado un acervo comunitario sobre igualdad de sexos de gran amplitud e importante calado». Las diversas directivas europeas en torno a esta cuestión y las actuaciones del Parlamento Europeo y de la Comisión Europea han sido constantes en los últimos años. En el año 1990 se aprobó en el Consejo de Ministros de la Unión Europea una Recomendación sobre la eliminación del sexismo en el lenguaje. En esta norma se reconocía la existencia de obstáculos a la igualdad real entre hombres y mujeres, considerando que el lenguaje es un instrumento primordial en la formación de la identidad social de cada persona. Se proponían tres medidas: en primer lugar, que los Estados miembros incorporaran iniciativas para

\footnotetext{
${ }^{7}$ Consultada en https://bit.ly/3IpAGOr

${ }^{8}$ Consultada en https://bit.ly/3pB6jfm
} 
fomentar un lenguaje no sexista. En segundo lugar, que promovieran en textos jurídicos, educativos y de la administración pública el uso de terminología armónica con el principio de igualdad entre mujeres y hombres. Finalmente, que se fomentara la utilización de un lenguaje no sexista en los medios de comunicación y difusión.

El Consejo de Europa también ha mostrado una actividad contundente en cuanto a la lucha a favor de la igualdad entre mujeres y hombres. La regulación en el Convenio Europeo de Derechos Humanos es clásica y es el art. 14 el que decreta la prohibición de discriminación por razón de sexo (Carmona Cuenca, 2018, 311-334). El Protocolo n. ${ }^{\circ} 12$ del Convenio Europeo de Derechos Humanos reconoce la posibilidad de la utilización de las acciones positivas para intentar erradicar la desigualdad estructural e histórica entre mujeres y hombres. Con este reconocimiento, el Tribunal Europeo de Derecho Humanos ha dictado diferentes sentencias consolidando la igualdad entre mujeres y hombres (Carmona Cuenca, 2018, 324-332).

El artículo 14 de nuestra Constitución (CE) reconoce la igualdad ante la ley y la no discriminación por cualquier otra condición o circunstancia personal o social, y expresamente se refiere a la no discriminación por razón de sexo. La importancia de la ubicación de este precepto en el texto constitucional ya ha quedado acreditada por la doctrina y por la jurisprudencia constitucional (Alonso García, 1983, 21-92; Pérez Luño, 2007, 75-100). Que este artículo se encuentre dentro del Capítulo Segundo, del Título I, pero antes de la Sección $1^{\mathrm{a}}$, de dicho Capítulo Segundo, supone que todos los derechos reconocidos en él, tanto los derechos y libertades fundamentales como los derechos y deberes de la ciudadanía, deben ser siempre interpretados y desarrollados conforme al principio de igualdad recogido en ese artículo 14 (Pérez Luño, 2007, 75-100)9 . El art. 53.2 CE determina que el amparo judicial y el recurso de amparo pueden emplearse en caso de vulneración del art. 14 , lo que coloca a la igualdad como un derecho fundamental cuyo sistema de garantías es el más alto, tanto a nivel legislativo (sólo se podrá regular a través de una ley orgánica) como a nivel jurisdiccional (el amparo judicial y el recurso de amparo sólo se activan en caso de vulneración de un derecho fundamental). Todo ello nos sirve para entender que si el uso del lenguaje no sexista está amparado por este artículo constitucional, supone que su irradiación a todos los demás derechos es ineludible.

$\mathrm{El}$ art. 9.2 CE se ocupa de establecer la obligación de los poderes públicos de promover las condiciones para que la igualdad de las personas y de los

${ }^{9}$ La igualdad se recoge en nuestra Carta Magna como un valor superior del ordenamiento jurídico, como un principio y como un derecho. Esta triple conceptualización nos muestra la importancia de su existencia y su unión inquebrantable con el principio democrático. 
grupos en que se integran sean reales y efectivas. La igualdad material es el marco esencial para que se puedan desarrollar acciones positivas imprescindibles para alcanzar la igualdad real. Esta es una característica básica del Estado social de Derecho en el que quién ejerce el poder debe tener en cuenta la posición real de la ciudadanía para actuar en consecuencia y conseguir una equiparación efectiva (Giménez Gluck, 1999; Montilla Martos, 1997, 437464). Si se entiende que el uso del lenguaje es un mecanismo dentro de las acciones positivas para conseguir la igualdad real y efectiva, entonces su constitucionalidad es más que evidente.

La significación del artículo 14 es evidente, pero también resulta obvio a estas alturas de nuestro sistema democrático constitucional que el reconocimiento de la igualdad formal ante la ley no ha conseguido por sí solo acabar con la desigualdad estructural que sufren las mujeres. Por esta razón, la combinación con el precepto 9.2 CE es clave para luchar contra esta lacra. La violencia machista, la discriminación salarial, el mayor desempleo femenino, la desigual presencia en puestos de responsabilidad política, o la conciliación entre la vida personal, laboral y familiar siguen siendo algunos de los elementos por resolver en nuestras sociedades. Sólo la coordinación entre la igualdad formal y la igualad material puede ayudarnos a acabar con la discriminación de las mujeres, y conseguir la plena igualdad entre ambos sexos. Para ello, es insoslayable dotarse de nuevos instrumentos jurídicos. Pueden ser normativos, que algunos de ellos ya están incorporados a nuestro sistema de Fuentes del Derecho, pero también pueden ser acciones positivas destinadas para prevenir y suprimir esta discriminación o bien, a compensar las desventajas que resulten de las estructuras desiguales existentes. A veces, estas acciones formulan un derecho desigual en favor de las mujeres, pero las normas jurídicas en las que se amparan ya regulan aquellas cautelas y condiciones indispensables para que no se produzca ninguna inconstitucionalidad. La actuales leyes en esta materia se han consolidado como constitucionales y, por tanto, estas acciones positivas también. Los poderes públicos deben encargarse de la prevención de las conductas discriminatorias y de la previsión de políticas activas que hagan efectivo el principio de igualdad (López Guerra, 2000, 19-42; Rey Martínez, 1995, 31-75; Figueruelo, 2004, 1-10).

Por su parte, el lenguaje libre de sexismo no supone un derecho desigual en favor de las mujeres, sólo se busca dar visibilidad al sexo discriminado históricamente. No podemos olvidar que lo que no se nombra, no existe. El lenguaje es determinante en la representación de la realidad. Identificamos todo lo que nos rodea a través de los términos, las palabras que la lengua concede tanto a objetos materiales, como a situaciones, acciones o emociones. Nombrar las ideas, los objetos, los hechos, o a las personas supone hacerlas visibles. La realidad se construye con aquello que podemos identificar. Dentro del lenguaje, las mujeres y sus actuaciones han sido invisibilizadas en 
numerosas ocasiones. Otras veces, sus emociones o ideas han sido transmitidas de manera peyorativa. Por eso, trasladar al lenguaje la presencia real que las mujeres tiene en la vida es crucial para traspasar el umbral de la invisibilidad. El uso del lenguaje discriminando a las mujeres supone el incumplimiento tanto del art. 14 como del art. 9.2 CE. La consecución de la igualdad entre mujeres y hombres se tiene que dar en todos los niveles de nuestra vida. El lenguaje, que es una herramienta de comunicación y de formación debe ser utilizado para que represente a las mujeres y a los hombres y para evitar y erradicar el sexismo en el lenguaje.

\section{CONCEPTO Y SIGNFICACIÓN DEL LENGUAJE NO SEXISTA}

No estamos ante una temática reciente sino que ha sido estudiada con profusión por la lingüística desde los años setenta. La autora Robin Lakoff fue la primera que propuso el debate académico sobre cómo la relación de hombres y mujeres se materializaba en el uso del lenguaje, en 1973 (Lakoff, 1981). Este debate tuvo diferentes posturas y enfoques. La primera de ellas se preguntaba si había que llevar a cabo acciones que se encargaran de modificar el uso del lenguaje. Esta postura entiende que el lenguaje es sexista pero cree que lo que hay que hacer es focalizar la atención en la acción social igualitaria que acabará logrando que el uso sexista del lenguaje se acabe modificando naturalmente por este cambio social ${ }^{10}$. Así lo manifiesta la lingüista Anne Pauwels que a finales de los noventa mantiene que «Quienes apoyan la postura de que "el lenguaje refleja la realidad" se inclinan menos a promover una acción lingüística ya que dudan de que un cambio en el lenguaje lleve consigo el deseado cambio social. Argumentan que las prácticas sexistas en el lenguaje son el resultado de actitudes sexistas de quienes lo usan que además viven en comunidades que no promueven un tratamiento igualitario entre mujeres y hombres. (...) Por otro lado la postura de que «el lenguaje refleja la realidad social» no excluye del todo la pertinencia o incluso la necesidad de implementar una acción lingüística. De hecho, un grupo importante de quienes proponen guías oficiales para un uso no sexista de la lengua, suscriben este punto de vista y, no obstante, argumentan a favor del cambio porque el cambio en la lengua va por detrás de los cambios en las prácticas sociales y culturales» (Pauwels, 1998, 84-85).

Frente a esta postura se encuentra aquella que defiende la necesidad de crear acciones que intervengan en el lenguaje para conseguir que su uso esté libre de sexismo. Es imprescindible que la acción social en busca de la igualdad entre mujeres y hombres se complemente con actuaciones sobre el

${ }^{10}$ Consultado en https://bit.ly/31HTlv7 
lenguaje. Atacar la discriminación desde todos los ámbitos será más eficaz que esperar que una acción general y abstracta contra la desigualdad consiga erradicarla en todos los niveles de la sociedad. De esta manera, hay que trabajar sobre la planificación lingüística. Esta planificación debe basarse en cinco fases: «la detección del problema, la planificación, la implementación, la evaluación y la retroalimentación» (Pauwels, 1998, 7-9). Esta postura es la que han tomado las instituciones internacionales, europeas y nacionales actuales.

Entonces, ¿cómo podemos definir el lenguaje sexista? A lo largo de estas páginas se ha hablado frecuentemente del lenguaje o sexista y de su constitucionalidad. Pero creo que llegados a este punto, debemos detenernos en discernir qué es el lenguaje sexista, con el fin de poder saber también cuándo nos encontramos ante el adecuado uso no sexista del lenguaje. Por lenguaje sexista se entiende aquel que hace uso en exclusiva de uno de los géneros, el masculino, para referirse a los dos, excluyendo al otro, ya sea voluntaria o involuntariamente (Bolaños Cuéllar, 2013, 89-110; Lozano Domingo, 1995; Calero Fernández, 1999). De esta manera, las mujeres quedan invisibilizadas, produciendo situaciones en las que el abuso del uso genérico masculino de los términos supone que no seamos capaces de identificar a mujeres en puestos como el de la presidencia del Gobierno. Por ende, cuando hablamos de lenguaje no sexista, nos referimos al uso en el cual las mujeres y hombres quedan visibilizados, evitando los prejuicios hacia un sexo en concreto (Sastre Ruano et al., 2003; Suardiaz, 2002).

Cuando se habla de lenguaje no sexista se puede pensar que se trata únicamente de desdoblar las palabras en el género masculino y femenino, utilizar símbolos que incluyan a ambos sexos en el lenguaje o meras sustituciones de términos. Pero las reglas para la utilización del uso adecuado y no sexista del lenguaje son mucho más profundas. Se trata de «armonizar con sentido común varios criterios: la norma gramatical, la coherencia textual, el contexto situacional y los ámbitos o géneros discursivos» (Briz Gómez coord., 2001, 21). Podemos decir que per se, la forma masculina no es sexista, que el desdoblamiento no es incorrecto ni obstaculiza el lenguaje, ni que la sustitución de un término por otro abstracto o colectivo impide el sexismo. El acondicionamiento de estas alternativas va a depender el contexto y del ámbito, del género discursivo, del canal de comunicación, del registro, o de las personas a las que se apele (Briz Gómez coord., 2001, 22-23).

Las posturas contrarias al uso no sexista del lenguaje manifiestan que la utilización del masculino genérico se utiliza por el principio de economía lingüística. Es el caso de la propia Real Academia Española de la Lengua (RAE). No obstante, si se consultan las guías elaboradas por diferentes instituciones públicas y privadas, se puede observar que los desdoblamientos no 
son la regla general del lenguaje no sexista ${ }^{11}$. Por otro lado, aducen que el uso de términos genéricos puede llevar a impersonalizar el contexto. Si utilizamos alumnado en vez de alumnos, parece que se aleja del trato más personal. Sin embargo, esta es una percepción cultural y subjetiva que puede cambiar ya que el lenguaje evoluciona constantemente, y no se incumple ninguna regla gramatical haciendo uso de este recurso. El último argumento al que me quiero referir es aquel que aduce que si no existe una intención ex profesa de discriminar, no hay por qué cambiar el lenguaje. El problema radica en que, en general, la discriminación de las mujeres - como de otros grupos- no se produce frecuentemente de forma consciente. Todo lo contrario, el gran problema para acabar con esta desigualdad reside en que se genera de forma involuntaria y que ser consciente de ello es sumamente complejo (García Campaña et al., 2018, 144-153; Aznar Minguet, 2008, 33-63; Díaz Hormigo, 2018, 267-274).

Es ahora el momento de observar los condicionantes que pueden provocar la discriminación en el lenguaje y que afectan a cómo utilizar el lenguaje en cada momento. Con respecto a cuáles son las reglas gramaticales para hacer un uso correcto del lenguaje ya se han mencionado las numerosas guías y documentos realizadas por expertos y expertas lingüistas que tienen un gran valor y arrojan luz a esta cuestión. Por esta razón, los próximos párrafos se detendrán en los elementos que hay que tener en cuenta a la hora del uso del lenguaje libre de sexismo, esto es, el contexto y en concreto el ámbito, el género discursivo, el canal de comunicación, el registro o las personas a las que se apela.

Cuando hablamos del contexto y nos referimos en especial al ámbito, estamos haciendo alusión a si nos encontramos en un ámbito administrativo, educativo, social, artístico, etc. Dependiendo del entorno en el que nos ubiquemos el lenguaje deberá desarrollarse de una manera o de otra. El ámbito administrativo y educativo deben visibilizar claramente la igualdad entre mujeres y hombres. La vinculación de la Constitución a los poderes públicos supone un deber general positivo de desempeñar sus funciones y competencias siempre de acuerdo con los preceptos constitucionales. Ello no significa una adhesión ideológica ni conformidad con todo su contenido, pero sí el respeto de esta. Por esta razón, para dar cumplimiento al art.9.2 CE y a las políticas públicas que se han tomado conforme a este precepto, hay que observar adecuadamente el uso del lenguaje no sexista. Para conseguir la igualdad real y efectiva no sólo se necesita la responsabilidad de los poderes públicos, sino también la participación en este ámbito del sector privado y de las relaciones entre los particulares.

${ }^{11}$ Por ejemplo, las «Guías papa el uso no sexista del lenguaje» realizado por el Instituto de la Mujer, consultado en https://bit.ly/3y4g09W. O la «Guía de lenguaje no sexista» realizado por la UNED. Consultado en https://bit.ly/3y7jmJ4 
Obviamente, se tiene que respetar los principios de libertad y autonomía contractual, pero hay que coordinarlos con la promoción de la igualdad entre mujeres y hombres. En este sentido, ¿en los ámbitos de índole privada no deben utilizar lenguaje libre de sexismo? la respuesta es sí, deben hacerlo, así lo establece nuestro ordenamiento jurídico. Ahora bien, hay veces que el contexto puede necesitar que no se produzca un desdoblamiento o el uso específico de la palabra «ciudadano», en vez del término más genérico «ciudadanía». Habrá que asegurarse de poder hacer un uso adecuado del lenguaje manteniendo la esencia del contenido del discurso. Por otro lado, podemos encontrarnos con la traducción actual de una obra del siglo XIX, ¿es necesario utilizar lenguaje no sexista aunque el autor o la autora no lo utilizara por pertenecer a otra época?

En relación al género discursivo, nos referimos a si estamos ante una conversación, una entrevista, una conferencia, una carta, una convocatoria, un formulario, un programa de televisión o un programa de radio, entre otros. No significa que en algunos de estos géneros se pueda utilizar un lenguaje sexista, no es esa la problemática, sino dilucidar cuáles serán las reglas del uso de lenguaje libre de discriminación más convenientes para cada género discursivo. Por lo que respecta al canal del comunicación hay que observar si se produce de manera oral o escrita. Un escrito debe poner una mayor atención en cuanto al uso del lenguaje no sexista, por la capacidad de revisión y de observar con detenimiento las reglas necesarias para evitar cualquier tipo de discriminación. En un canal de comunicación oral es más difícil controlar en cada momento el uso de este lenguaje no sexista. No obstante, el conocimiento de las reglas propuestas por los lingüistas a tal efecto y la asimilación de las mismas ayuda a poder utilizar fluidamente de forma oral un lenguaje libre de sexismo.

Cuando se habla del registro, se hace referencia a si éste es formal o coloquial. El registro formal es el que se desprende de la norma culta de la lengua. Es el lenguaje que se aprende en los años de formación. En este caso, la exigencia del lenguaje no sexista es mucho mayor que en el caso de un registro más coloquial. Finalmente, hay que tener en cuenta a las personas a las que se apela. Si se apela en exclusiva a un público masculino, por ejemplo, no tiene ningún sentido realizar un desdoblamiento, lo mismo que si se apela a un público femenino no se puede utilizar el género masculino como genérico. Ahora bien, una cosa es saber a quién se está apelando y otra bien distinta es que el contenido que se pueda desarrollar ante ese público esté libre del uso del lenguaje no sexista.

\section{INFORME DE LA REAL ACADEMIA ESPAÑOLA SOBRE LA INCLUSIÓN DE LENGUAJE NO SEXISTA EN LA CONSTITUCIÓN ESPAÑOLA}

El 16 de enero de 2020, la Real Academia Española (RAE) publicó su informe sobre la idoneidad de incluir el uso del lenguaje inclusivo en la 
Constitución española, tras atender a la solicitud de la Vicepresidenta del Gobierno, Doña Carmen Calvo Poyato, sobre este asunto. Este informe desaconseja reformar la Carta Magna para adecuarla al lenguaje inclusivo. Con este fin, expone diferentes argumentos para justificar esta postura. No se trata en este trabajo de analizar uno a uno todos los puntos desarrollados en el mencionado informe, en primer lugar, porque existen cuestiones que son propias de la lingüística y que escapan a los conocimientos de una constitucionalista. En segundo lugar, porque hay razonamientos en el estudio de la RAE que pueden ser aceptables y válidos. Lo que se va a tratar de hacer en los siguientes párrafos es poner de manifiesto que algunos de ellos pueden ser rebatidos en cuanto al uso del lenguaje no sexista.

La reforma constitucional se ha convertido en un tema complejo con difícil solución y sin visos, actualmente, de conseguir las mayorías parlamentarias necesarias para llevarla a cabo (Pérez Tremps, 2018, 25-96; López Aguilar, 2021, 199-218). Temas fundamentales como la derogación de la preferencia del varón sobre la mujer en la sucesión al trono para que no haya contradicciones dentro del propio texto constitucional, o la necesaria reforma autonómica no parecen prontas a su modificación. La inclusión del lenguaje no sexista en los artículos constitucionales está revestida de una fuerte polémica donde no parece que tampoco haya consenso. Por esta razón, también parece complicada su posible reforma. Aunque el informe de la RAE no sea vinculante y, por tanto, sea posible modificar el texto para incluir un lenguaje libre de sexismo, otros son los problemas que acontecen en esta y en otras propuestas de reforma constitucional. En recientes declaraciones a la Cadena SER, el Presidente del Tribunal Constitucional, Don Pedro González-Trevijano Sánchez, expuso claramente que «por un lado las constituciones tienen vocación de permanencia y estabilidad porque establecen las reglas fijas de convivencia, pero simultáneamente, y lo decía el presidente Jefferson, y yo lo comparto, las generaciones modernas, las generaciones venideras tienen derecho a organizar su vida jurídico política de acuerdo con las exigencias de los nuevos tiempos. En consecuencia y con carácter general, reformar la Constitución y acomodar algunos puntos a las nuevas exigencias de los tiempos me parece una medida en principio válida $\mathrm{y}$, en segundo lugar, razonable $[\ldots]\rangle^{12}$.

12 Declaraciones realizadas en la Cadena SER el día 7 de diciembre de 2021, transcripción propia. El Presidente del Tribunal Constitucional continúa: «[...] Siempre que se insta a un proceso de reforma constitucional los catedráticos en la universidad solemos establecer una hoja de ruta. La hoja de ruta consiste en abrir la reforma de la Constitución en momentos de distención política y antes de abrir la reforma de la Constitución hay que saber tres cosas: primero, qué se reforma, segundo, porqué se reforma y tercero, de acuerdo con qué criterios se reforma». Consultado en https://bit.ly/3DtQ5tm 
En cuanto al informe de la RAE, lo primero que dice es que esta institución toma «como referencia el uso mayoritario de la comunidad hispanohablante en todo el mundo». Además, manifiesta que el fin de esta Academia no se encuentra en impulsar, dirigir o frenar los cambios lingüísticos. Estos cambios deben venir de manera natural y espontánea de las personas hablantes. Por otro lado, define a la Constitución como «un modelo del uso común del español, y que ello ha de ser compatible con que se perciba en él su valor político como la más alta declaración de los derechos y deberes de todos los ciudadanos, sea cual sea su sexo, y especialmente como símbolo de su igualdad efectiva en todos los ámbitos de la sociedad». En relación con los derechos y deberes nuestra declaración constitucional reconocida en el Título I recoge expresiones que por su formulación son completamente compatibles con un lenguaje no sexista. Por ejemplo, la utilización de formas impersonales, como las del art. 16, o la utilización de «toda persona» en el artículo 17. En otras ocasiones las expresiones «los españoles»o «los ciudadanos» han acarreado más problemas. El dilema aquí se planteó en torno a si las personas extranjeras podían ser titulares de estos derechos. El artículo 14 habla de los españoles y el artículo 23 menciona exclusivamente a los ciudadanos. Estos casos fueron resueltos por nuestro Tribunal Constitucional (STC 107/84). Ambos son derechos fundamentales que pueden entenderse como universales, no obstante, su formulación no daba a entender esto. De ahí la importancia del uso del lenguaje. Nuestro Alto Tribunal estableció que los derechos fundamentales son imprescindibles para garantizar la dignidad de las personas y que, por tanto, las personas extranjeras podían ser titulares de estos derechos, exceptuando los derechos de participación política, esto es, los del artículo 23 ya que la propia Constitución los excluía. Esa exclusión tiene que ver con el término «ciudadanos» utilizado en dicho precepto. Sin embargo, la expresión «los españoles» del artículo 14 no podía excluir a las personas extranjeras de ser titulares del derecho a la igualdad ante la ley. De ahí que la utilización de uno y otro término no resulte baladí y pueda dar lugar a ambigüedades que planteen dificultades constitucionales.

La RAE manifiesta que el uso del género masculino es perfectamente legítimo e incluye a los dos sexos, pero ya hemos podido observar que esta es una cuestión que se viene investigando y desarrollando desde los años setenta del siglo XX. De esta manera, esta Academia obvia en todo su informe este debate así como la legislación actual sobre lenguaje no sexista, y las guías utilizadas por todas las Administraciones Públicas que contemplan reglas lingüísticamente adecuadas para dejar de utilizar de forma abusiva del masculino genérico. Ya hemos visto que no se trata de hacerlo desaparecer, pero sí de limitar un uso que puede ser perjudicial y puede perpetuar una de las discriminaciones prohibidas específicamente por el artículo 14 de nuestra Carta Magna. 
En este mismo sentido, la RAE recoge una afirmación curiosa: «En ciertos casos, poco numerosos, el masculino plural no se usa en español con interpretación inclusiva. Es raro que la expresión los enfermeros abarque a las enfermeras, y más raro todavía que la expresión los monjes comprenda a las monjas, o que los brujos incluya a las brujas. En el primer caso (enfermeros) la ausencia de interpretación inclusiva se debe a la tradicional prevalencia de la mujer en el desempeño de la enfermería [...] Como es lógico, si se desea hacer referencia a las mujeres en todos esos casos, será necesario usar fórmulas que las abarquen explícitamente». Como la enfermería es una profesión de mujeres, se entiende que cuando se alude a los enfermeros sólo se refiere a hombres que realizan esta profesión. Este es un caso claro de las paredes de cristal. La discriminación por razón de sexo ha creado muros invisibles que compartimentan el desarrollo profesional. Se produce una segmentación horizontal donde la mujeres trabajan en sectores con una remuneración menor y un menor dinamismo. Ellas trabajan en los sectores más relacionados con el cuidado, como puede ser el sector de la salud. (Nuño Gómez, 2009, 205232El artículo 27 de la Constitución habla de «profesores». En esta profesión, en 2019, el 65\% eran mujeres, y en enseñanzas no universitarias ese porcentaje aumentaba hasta el $71,9 \%{ }^{13}$. Es decir, que estamos ante una profesión donde la prevalencia de la mujer es significativa, y no sólo en los últimos años. Sin embargo, la RAE entiende que en este caso es adecuado el uso del género masculino para abarcar a ambos sexos. El uso sexista del lenguaje se observa claramente cuando se utiliza un término en masculino siendo el referente apelado mayoritario las mujeres (Briz Gómez, 2011, 117).

Por lo que respecta al uso de una construcción impersonal, la RAE piensa que hacerlo de manera general y sistemática puede crear un texto indeterminado y ambiguo. Es más, mantiene que esto puede acarrear una discriminación hacia los varones, sin desarrollar el porqué de esta afirmación. No obstante, si acudimos de nuevo al Título I de la Constitución, aquel que apela más concretamente a la ciudadanía, encontramos constantemente construcciones impersonales tales como «Se garantiza», «Nadie», «Toda persona», «Se reconocen», que se repiten asiduamente en dicho título, mucho más que el masculino genérico o las expresiones «los españoles»o «los ciudadanos». En otros Títulos de la Constitución, donde se mencionan instituciones propias de nuestra separación de poderes no parece muy perjudicial utilizar «presidencia del Gobierno» en vez de «presidente del Gobierno». Ya sabemos que lo que no se nombra no existe y crear una fórmula en la que puedan incluirse los dos sexos sin discriminar a ninguno, puede ser beneficioso para la consecución de la igualdad entre mujeres y hombres.

${ }^{13}$ Consultado en el Ministerio de Educación y formación profesional https://bit. ly/31LW6vs 
En las conclusiones del informe, la RAE manifiesta que frente a las dos interpretaciones de la expresión lenguaje inclusivo, la Constitución de 1978 opta por la segunda. Estas dos interpretaciones, que se exponen al principio del informe son, en primer lugar, la restrictiva donde las referencias expresas a las mujeres se producen a través de palabras de género femenino o usando términos que rehúyan el uso masculino como genérico. En segundo lugar, se encuentra la interpretación más amplia que ampara que los términos en masculino incluyen a hombres y mujeres cuando el contexto es claro. Desde mi punto de vista, el informe de la Academia se ha basado únicamente en el método gramatical de aplicación de las normas jurídicas, sin tener en cuenta otros métodos de interpretación que se deben aplicar a nuestra Constitución. El método sistemático dispone que hay que acercarse al texto normativo en relación con su contexto. No hay que tomar frases aisladas porque pueden parecer tener un significado que no es (STC 103/1990). Asimismo, el método histórico tiene en cuenta los antecedentes históricos y legislativos (SSTC $67 / 1983,94 / 1985,120 / 1987)^{14}$. Las normas deben interpretarse observando las razones y las circunstancias sociales de la época en la que la norma se aprobó $^{15}$ (García Cuadrado, 2002, 219-220). Por esa razón, teniendo en cuenta que el texto constitucional es de 1978, que el debate sobre el lenguaje no sexista se había abierto pocos años antes en los Estados Unidos de América y todavía no había llegado con toda su fuerza a España, no parece que los constituyentes decidieran decantarse por la interpretación amplia de la expresión lenguaje no sexista o inclusivo frente a la interpretación restrictiva. La RAE otorga al poder constituyente español una decisión inverosímil teniendo en cuenta el método de interpretación histórico y sociológico.

Con respecto al análisis comparativo que se hace en este estudio, se han utilizado cuatro países hispanohablantes (Chile, Colombia, México y Venezuela) y tres países de Europa en los que se habla una lengua románica (Francia, Italia y Portugal). Sólo en una de las Constituciones investigadas se utiliza un lenguaje no sexista, la venezolana de 2009 , la más reciente. No se menciona explícitamente el año de publicación de ninguna otra de estas Constituciones lo que, a mi modo de ver, es una laguna destacable. Las Constituciones europeas analizadas fueron aprobadas en 1947 (Italia), 1958 (Francia) y 1976 (Portugal). La Constitución mexicana es de 1917 y la colombiana de 1991. La Constitución chilena es de 1980 pero dado el proceso de elaboración de una

${ }_{14}$ En la STC 27/1981, el Alto Tribunal dijo que «el ordenamiento jurídico, por su propia naturaleza, se resiste a ser congelado en un momento histórico determinado: ordena relaciones de convivencia humana y debe responder a la realidad social de cada momento, como instrumento de progreso y perfeccionamiento.» (Fundamento Jurídico 10).

${ }_{15}$ Además de los tres métodos señalados hay que incluir el método teleológico o finalista cuyo fin es observar el espíritu y la finalidad de la Constitución, y el método comparado. 
nueva Constitución, creo que sería aconsejable esperar a ver qué va a pasar con este aspecto en el próximo texto constitucional chileno. Algunas de las fechas indicadas son anteriores a que se iniciara el debate sobre el lenguaje no sexista y otras, aunque su aprobación fue posterior, no era una cuestión que tuviera la fuerza que posee actualmente, y no existían normas en los sistemas de Fuentes del Derecho que regularan el uso del lenguaje libre de sexismo. Lo que sí que creo que podría haber apuntado la RAE es el fenómeno que se puede observar de esta comparación, y es que cuando se elabora una nueva Constitución se tiene en cuenta el lenguaje que esta institución denomina como inclusivo, mientras que algunas constituciones ampliamente reformadas, como la francesa o la italiana no han introducido este lenguaje. El método comparado de interpretación es muy adecuado pero también hay que tener en cuenta que se puede avanzar más allá de los países cercanos en materia de derechos y libertades, como es el caso del matrimonio entre personas del mismo sexo que fue aprobado por primera vez en Países Bajos en el año 2000 y actualmente se extiende a más de treinta países de todo el mundo.

\section{CONCLUSIONES}

El uso del lenguaje no sexista ha sido introducido en nuestro ordenamiento jurídico a través de diferentes normativas tanto internacionales, europeas, como nacionales, en su acepción central y en su acepción autonómica. Dicha normativa no obliga a su utilización ni impone sanciones en caso de no hacerlo, pero lo que sí que demuestra es que esta cuestión cada vez va adquiriendo más importancia y se ha convertido en un componente crucial para intentar conseguir la igualdad entre mujeres y hombres. Su importancia simbólica, por un lado, y material por otro, no dejan duda a que en los próximos años su aplicación podrá ir aumentando, sobre todo en los espacios públicos.

La constitucionalidad del lenguaje libre de sexismo ha quedado patente tras analizar el artículo 14 y el artículo 9.2 de nuestra Constitución. La consecución de la igualdad formal y efectiva pasa por tomar medidas eficaces que ayuden a acabar con esta discriminación. El mandato que el precepto noveno da a los poderes públicos abre la puerta a crear y tomar acciones positivas cuyo objetivo sea acabar con la desigualdad histórica y estructural que sufren las mujeres. Se ha podido observar que no es un problema propio de España, sino que la utilización de un lenguaje no sexista debe ser una disposición general para todo el planeta. Sólo así se podrá consensuar una nueva manera de hablar y comunicarse.

El empleo del lenguaje no sexista ha sido y es un tema sumamente polémico que ha establecido posiciones muy encontradas y de difícil acercamiento. El miedo a modificar el lenguaje de manera abrupta planea sobre la doctrina contraria a esta utilización del lenguaje. Sin embargo, y consultado 
con profundidad las guías de comunicación no sexista (Briz Gómez, 2011), se puede poner de relieve que las posiciones favorables a un lenguaje libre de sexismo no intentan crear reglas nuevas ni hacer cambios sustanciales en el lenguaje, simplemente buscan utilizar las normas existentes de la lingüística para adecuarlas a la visibilización de los dos sexos cuando procedemos a comunicarnos. Cuando no nombramos una persona, un sentimiento, una acción, un objeto, entonces lo estaos destinando a su inexistencia. Su posición en la sociedad comienza por su nombramiento. Los defensores liberales de los derechos y libertades tenían claro que estos eran inalienables y pertenecían a los individuos por el mero hecho de serlo. De esta manera, los derechos y libertades no pertenecían a ninguna organización política, por eso las declaraciones sólo se encargaban de afirmarlos, no de concederlos ni otorgarlos. Una parte doctrinal y política mantenía que gracias a esta teoría no hacía falta realmente que los derechos se recogieran en la Constitución (Baylin, 2012, 191-193). Este posicionamiento rápidamente quebró: que expresamente el texto constitucional reconociera y nombrara los derechos y libertades era esencial para su cumplimiento y garantía.

La discusión sobre la necesidad de usar un lenguaje libre de sexismo nace en los años setenta del siglo XX en los Estados Unidos de América, aunque no será hasta principios del siglo XXI que se extenderá entre el discurso académico y las esferas políticas y sociales. El lenguaje en principio no es sexista, es el uso que de él se haga el que provoca situaciones donde el sexo femenino se encuentra en una posición de inferioridad. Hay toda una serie de elementos que influyen en este uso y que deben ser considerados a la hora de trazar las reglas necesarias para conseguir emplear el lenguaje sin que provoque discriminación. Estos elementos son el contexto y en concreto el ámbito, el género discursivo, el canal de comunicación, el registro o las personas a las que se apela.

En el año 2020 la Real Academia española publicó un informe sobre la idoneidad de modificar nuestra Carta Magna e introducir un lenguaje no sexista en sus preceptos. Su conclusión fue que no era necesario realizar esta reforma. No obstante, y desde mi punto de vista, este informe muestra algunas lagunas destacables en cuanto a la justificación de esta decisión. Parece, tras la lectura de dicho estudio, que hay una especial preocupación por el desdoblamiento de las palabras en género masculino y femenino. En cambio, ninguna de las guías consultadas aconseja la utilización constante y automática de dichos desdoblamientos. Además, se puede entender que el uso masculino genérico puede utilizarse de vez en cuando, y cuando el contexto lo requiera, pero sin abusar de él. No queda tan claro porqué las fórmulas impersonales pueden discriminar al varón, como se recoge en la página 89 de dicho informe. Lo cierto es que la Constitución ya recoge numerosas construcciones impersonales, sobre todo en su Título I. La defensa acérrima de 
que las profesiones se puedan nombrar sólo con el género masculino queda fuera de cualquier recomendación realizada en torno al uso del lenguaje no sexista. Incluso lingüistas que no son defensores de dicho uso entienden que en las profesiones se debe hacer referencia al género concreto del profesional, o sustituirlo por un término que pueda englobar a ambos sexos.

El uso del lenguaje libre de sexismo es una realidad que ha sido expresada de diferentes maneras en muchos foros, económicos, sociales, políticos, culturales, académicos, de investigación. Podemos observar que hay una inquietud cada vez más acuciante con respecto a este asunto que afecta al $51 \%$ de la población mundial. Intentar que no se tenga en cuenta y que no se produzca una evolución en el lenguaje hacia esta dirección no parece una decisión acertada. Sobre todo porque actualmente poseemos un gran número de documentos académicos y de investigación que marcan unas pautas coherentes y que consiguen complementar la esencia de nuestra lengua con una evolución hacia la erradicación de la discriminación por razón de sexo también en esta dimensión.

\section{BIBLIOGRAFÍA}

Alonso García, E. (1983). «El principio de igualdad del artículo 14 de la Constitución española». Revista de Administración Pública, no ${ }^{\text {os }}$ 100-102. Enero-diciembre.

Aznar Minguet, P. (2008). Educación, género y políticas de igualdad. Valencia: Universidad de Valencia.

BAILyN, B. (2012). Los orígenes ideológicos de la Revolución norteamericana. Madrid: Tecnos.

Bolaños CuÉllaR, S. (2013). «Sexismo lingüístico: aproximación a un problema complejo de la lingüística contemporánea». Forma y Función, 26(1), págs. 89-110.

Bolívar, A. (2019). «Una introducción al análisis crítico del 'lenguaje inclusivo'». Literatura y Lingüistica, n. $^{\circ} 40$.

Bosque Muñoz, J. I. Coord. (2009). Nueva gramática. Morfología y sintaxis, Madrid: Real Academia Española.

Briz Gómez, A. Coord. (2011). Guía de comunicación no sexista, Madrid: Instituto Cervantes.

Calero Fernández, M. ${ }^{a}$ A. (1999). Sexismo lingüístico. Análisis y propuestas ante la discriminación sexual en el lenguaje. Madrid: Narcea.

Carmona Cuenca, E. (2018). «Los principales hitos jurisprudenciales del Tribunal Europeo de Derechos Humanos en materia de igualdad de género». Revista Teoría y Realidad Constitucional, n. ${ }^{\circ} 42$.

DíAz Hormigo, M. T. (2018). «Repercusiones y vigencia del uso de las propuestas para evitar la denominada 'discriminación lingüística por razón de sexo'». Actas do XIII Congreso Internacional de Lingüística Xeral, Vigo, 26.

Figueruelo BurRiezA, A. (2004). «La mujer en la Constitución española». Letras Jurídicas, volumen 9, enero-junio. 
García Campaña, A., Hidalgo Lacalle, M., López León, M. C., Román AlmenDROS, M. R. (2018). «Los micromachismos en los adolescentes. Su asociación con las relaciones de pareja y el modelo de maternidad y paternidad». Revistas - Cultura de los Cuidados - Año XXII, n. ${ }^{\circ} 51$.

García Cuadrado, A. Ma . (2002). El ordenamiento Constitucional (un enfoque histórico y formal de la Teoría de la Constitución y de las Fuentes del Derecho), Alicante: Editorial Club Universitario.

Giménez GlucK, D. (1999). Una manifestación polémica del principio de igualdad. Acciones positivas moderadas y medidas de discriminación inversas, Valencia: Tirant lo Blanch.

LAKOFF, R. (1981). El lenguaje y el lugar de la mujer, Barcelona: Editorial Hacer.

LóPEZ AguiLAR, J. F. (2012). «De la constitución irreformable a la reforma constitucional exprés». Teoría y Realidad Constitucional, n. ${ }^{\circ} 29$.

LóPEz GuERRA, L. (2002). «Igualdad, no discriminación y acción positiva en la C.E. de 1978». En AAVV. Mujer y Constitución en España, Madrid: Centro de Estudios Políticos y Constitucionales, 2000.

Lozano Domingo, I. (1995). Lenguaje femenino, lenguaje masculino. ¿Condiciona nuestro sexo la forma de hablar? Madrid: Minerva Ediciones.

Montilla Martos, J.A. (1997). «El mandato constitucional de promoción para la igualdad real y efectiva en la jurisprudencia constitucional. Su integración con el principio de igualdad». En AAVV. Estudios de Derecho Público (Homenaje a J.J. Ruiz-Rico). Madrid: Tecnos.

Nuño Gómez, L. (2009). «El empleo femenino en España y en la Unión Europea». Revista de Investigaciones Feministas, vol. 1.

Pauwels, A. (1998). Women changing languaje, London \&New York : Addison Wesley Longman.

Pérez Luño, A. E. (2007). Dimensiones de la igualdad. Cuadernos «Bartolomé de las Casas», n. ${ }^{\circ}$ 34. Madrid: Dykinson.

PÉREZ TREMPs, P. (2018). Las reformas de la Constitución hechas y no hechas. Valencia: Tirant lo Blanch.

Rey MARTínez, F. (1995). El derecho fundamental a no ser discriminado por razón de sexo, México: Consejo nacional para Prevenir la Discriminación.

Sastre Ruano, M. a A., Calero Vaquera, M. L., Lliteras, M. (2003). Lengua y discurso sexista. Guía de estilo 1. Valladolid: Junta de Castilla y León.

SuARDiAz, D. E. (2002). El sexismo en la lengua española. Zaragoza: Libros Pórtico. 


\title{
EL USO DEL LENGUAJE NO SEXISTA COMO INSTRUMENTO PARA CONSEGUIR LA IGUALDAD REAL Y EFECTIVA
}

\author{
The use of non-sexist language as a tool \\ to achieve real and effective equality
}

\author{
Cecilia Rosado-Villaverde \\ Profesora Contratada Doctora de Derecho Constitucional \\ Universidad Rey Juan Carlos
}

http://dx.doi.org/10.18543/ed-69(2)-2021pp229-248

\section{Copyright}

Estudios de Deusto es una revista de acceso abierto, lo que significa que es de libre acceso en su integridad. Se permite su lectura, la búsqueda, descarga, distribución y reutilización legal en cualquier tipo de soporte sólo para fines no comerciales, sin la previa autorización del editor o el autor, siempre que la obra original sea debidamente citada y cualquier cambio en el original esté claramente indicado

Estudios de Deusto is an Open Access journal which means that it is free for full access, reading, search, download, distribution, and lawful reuse in any medium only for non-commercial purposes, without prior permission from the Publisher or the author; provided the original work is properly cited and any changes to the original are clearly indicated. 